\title{
LEAN RENOVATION - A CASE STUDY OF PRODUCTIVITY, FLOW, AND TIME IMPROVEMENTS
}

\author{
Peder Johansen ${ }^{1}$, Søren Christensen ${ }^{2}$, Hasse H. Neve ${ }^{3}$, and Søren Wandahl ${ }^{4}$
}

\begin{abstract}
Renovation is a particular branch of construction where the production condition is more chaotic and complex than new build. Nevertheless, renovation as a production system has attained less focus than other project types in the Lean Construction community. Moreover, renovation is a significant driver for the green transition. Thus, knowing how to enable high-performing renovation projects is essential to disseminate both in academia and in the industry.

This industrial paper documents the improvement and turnaround of a renovation project faced with cost and time overruns.

The case was changed by implementing first the Last Planner System and daily huddles meeting, and later extending with the implementation of Location-Based Scheduling and a developed concept of visible site management. The entire transformation was monitored as productivity data were collected longitudinally during three years.

The result was a productivity improvement of 54\%, achieved even though the contractor capitalized on the productivity improvement by reducing the on-site workforce by $25 \%$ and still manage to complete the project one month ahead of the deadline.
\end{abstract}

\section{KEYWORDS}

Lean, renovation, productivity, case study.

\section{INTRODUCTION}

Lean construction has often been reported to improve construction projects successfully. However, few case studies of renovation projects exist. In this paper, a case study of a renovation project in which flow and productivity were improved by more than $50 \%$ by means of lean construction implementation is reported. It is also the story of a turnaround of a project faced with budget and time overrun. By focusing on flow and productivity improvements, it was achieved to reduce the on-site labor force by $25 \%$, the budget was enforced, and the project was completed one month in advance.

Renovation is a particular branch of construction where the production condition gets even more chaotic and complex than new build (Bertelsen 2003). Recent work by

\footnotetext{
Market director, Enemærke og Petersen a/s, Denmark, pej@eogp.dk, +45 91376708

Proces Manager, Enemærke og Petersen a/s, Denmark, sci@eogp.dk, +45 61938726

Consultant, Senior Associate, PhD, PwC, Aarhus, Denmark, +45 $2879 \quad 1838$, hasse.hojgaard.neve@ @wc.com, orcid.org/0000-0003-2311-3529

4 Professor, Dept. of Civil and Architectural Engineering, Aarhus University, Denmark, +45 4189 3216 , swa@cae.au.dk, orcid.org/0000-0001-8708-6035
} 
Kemmer (2018), Neve et al. (2020), and Tzortzopoulos et al. (2020) sheds light on renovation as a particular production system and points out that the main challenges are: 1) Existing building structure with a lot of unknown characteristics; 2) Dealing with tenants on-site; 3) Difficult construction site layout for logistics and material handling; 4) Highly specialized tasks and trades, i.e., removal of asbestos, etc. Kemmer (2018) reviewed the literature and points out that the traditional project management approach is insufficient in renovation and argues that lean management is superior. He argues that the traditional approach has a too-narrow focus on transformations, whereas lean expands to cover both transformations, flow, and value.

In the International Group for Lean Construction (IGLC), renovation projects and lean has mainly been investigated by Koskela, Kemmer, and Vrijhoef. Kemmer and Koskela (2012) started with an extensive literature review which revealed that the management of renovation works had not been appropriately addressed in prior research. They concluded that studies on practices applied to the management of this complex renovation system are scarce. Saurin et al. (2013) is exactly such a study of the Last Planner System (LPS) (Ballard 2000) implemented in renovation. The study was framed around construction as complex socio-technical systems, and they developed six guidelines for improved management which they tested on a renovation project. The conclusion was that the renovation project would have benefitted from having LPS implemented in addition to the six guidelines. However, they point out that LPS as a single tool is not sufficient for renovation. It needs to be supplemented with more training, leadership, and a better understanding of the complex socio-technical system. Kemmer and Koskela (2014) continued exploring renovation production systems with the aim to identify influential factors affecting planning and control effectiveness and the identification of the current managerial practices. They concluded that the most challenging characteristic of renovation is that works are carried out in an occupied building. Therefore, maintaining effective and constant communication with tenants is an essential competence for the contractor. Kemmer et al. (2016) continued the work of integrating LPS and renovation production systems. They found that regarding the benefits of utilizing LPS, there is a potential for reducing the disruptions on-site and compressing retrofit lead time. Improvements in communication and coordination were also noted as a result of the LPS adoption. In terms of implementation issues, the need to adapt the basic elements of LPS to suit the renovation context and get support from top management before start on site was identified as vital factors for successful application.

In continuation of the previous research on lean and renovation, this paper aims to report a case study where different lean tools helped improve flow and productivity and secured that the project was handed over to the client before schedule.

\section{METHODS}

The content of this paper is based on a case study. A single-case research approach was chosen. A case study allows for researching a single phenomenon in-depth but limits the ability to generalize the results beyond the single case study (Yin 2017). Nonetheless, this approach was perceived as valid for this topic.

The case selection criterion was that it should represent a typical renovation case, both in regards to the contractor's project portfolio but also with regard to the industry.

The primary data was quantitative data collected through Work Sampling (WS). Secondary data was unstructured and unrecorded qualitative information, observations, and reflections collected by the authors. The purpose was to enrich the quantitative data. 
However, these secondary data cannot be repeated as the secondary data collection unfolded in an informal and unstructured approach. WS is a quantitative method for assessing the efficiency of the workforce through observations. Observers walk around the construction site every hour and note the type of work carried out each time a craftsman is observed. This is categorized into seven predefined categories, where the first is Direct Work (DW), also called producing. Three categories fall into In-Direct Work, namely transporting, preparing, and talking. Finally, three categories of Waste Work, walking, waiting, and gone. WS data were collected four times during the construction period, cf. figure 2. Each data collection included five days of observations from production start in the early morning until production stopped in the afternoon. Research assistants were thoroughly instructed and supervised during the WS data collection. The moving average of each category was continually analyzed to ensure stability in the data, cf. figure 3,4 , and 5 .

\section{THE RENOVATION CASE}

The case is Fruehøj, a department in the Danish social housing company Fruehøjgaard. Fruehøj consists of 350 housing units established between the years 1953-1957. Windows was changed in the year 1987, and all apartments got new kitchens in the year 1992. The department consists of 19 blocks, all three stories high and with basement, cf. figure 1. A unit is a 2, 3, or 4-bedroom apartment from $53 \mathrm{~m}^{2}$ to $98 \mathrm{~m}^{2}$. All units are in one level only and include a small balcony. Besides, all units have a small storage room in the basement.
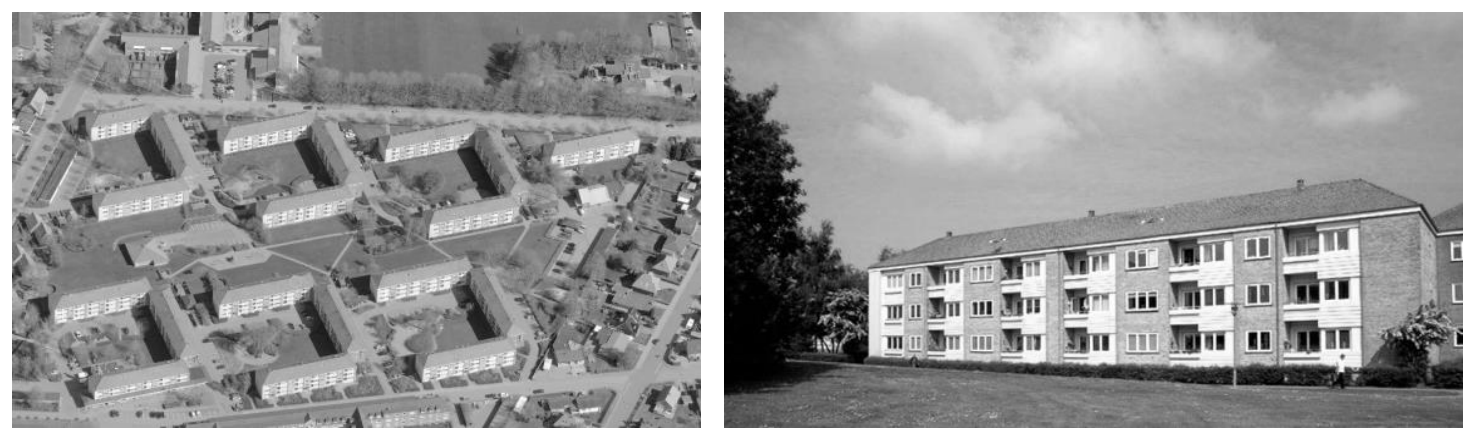

Figure 1. Picture of the housing department, showing its 19 blocks, three stories high.

Source: SDFE skråfoto (left), and Fruehøj.dk (right).

In the year 2013, the housing company initiated the process of an extensive renovation of all units. The construction period was scheduled from mid-2017 to early 2021. The Danish contractor Enemærke and Petersen was awarded the general contract after a public tender. The size of the contract was approximately USD 40 mill. It was a deep renovation where all units got a new kitchen, bathroom, facades, balcony, and completely new installations. All blocks got a new roof, improved insulation, and restored basements. Elevators were installed for 90 of the units. And several units were merged into larger units, resulting in 311 units after the renovation. In conclusion, it was a very extensive renovation, where units got upgraded to the current standard.

Figure 2 shows a milestone schedule of the project, including timestamps of productivity data collection on-site. 


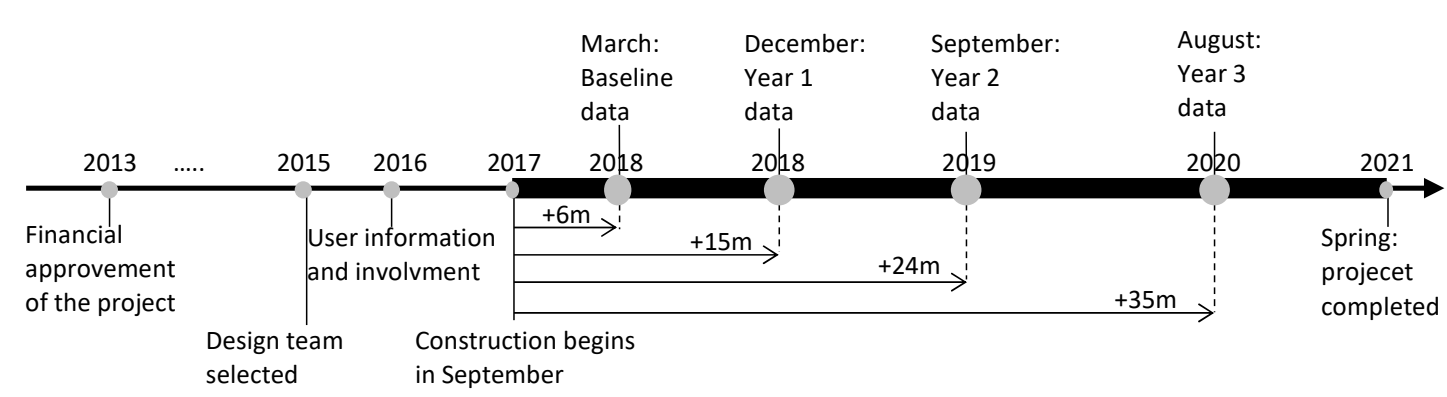

Figure 2. Milestone schedule and timestamps (months) for productivity collection.

The Fruehøj case is considered a 'normal' renovation case. It is a typical case for the contractor and is similar to many of the contractor's other renovation projects. In general, it is important that the case can be considered general so that learnings can be transferred to other renovation cases. Besides, the productivity data must be collected at the time of 'normal' production to ensure generalizability. Therefore, no data collection can be done within the first months of construction or if unique conditions arise, like holiday breaks, rough weather, delivery problems, etc.

\section{WORK DESCRIPTION}

Each block is renovated, following this overall description of process and work:

1. Tenants are relocated temporarily.

2. Demolition of all non-structural elements indoor and outdoor.

3. Establishing new elevator shafts and additional steel reinforcements.

4. The façade and roof are changed.

5. Masonry works are conducted. New internal walls \& closing off old openings.

6. Installations and electrical work, including new wiring, new pipes, new heating, new ventilation, new bathroom, and new kitchen installations.

7. Carpenter internal works, in the form of walls, ceilings, etc.

8. Masonry works in bathrooms, including titles, sink, toilets, etc.

9. Plastering and paintwork.

10. Flooring in all rooms and installation of new kitchens.

11. Completion, correction, and approval by the client.

12. Tenants move back and work moves on to the next block.

\section{LEAN ELEMENTS IMPLEMENTED}

The baseline data collection in spring 2018 was conducted under 'normal' production. At that time, the contractor only used their traditional project management method and had not implemented any lean production or planning methods. The baseline was deliberated delayed until six months after the first on-site activity to ensure that all facilities were up and running and to ensure that all initial learnings and start-up complications were due.

After the baseline data, the project management decided that actions were needed to improve flow and productivity on the site. Step-wise, the following lean methods were implemented on the project by the site management facilitated by the contractors' process support function. The progress was monitored in collaboration with researchers.

\section{Last Planner System (LPS)}

In mid-2018 (after the baseline data collection), LPS was partially implemented on the site. The project already had a master schedule. The process schedule was not implemented; instead, the master scheduled fed the making-ready planning process 
implemented with an eight-week lookahead. Site management ensured the seven flows and facilitated the weekly planning meetings, where foremen of each trade participated in planning next week's work. No systematic follow-up was implemented, and PercentPlanned-Completed (PPC) was not applied. The site management's implementation and facilitation of the LPS system were carried out solely without support from the contractor's central lean and process support division. It was exclusively the project and site managers who implemented and trained superintendents and subcontractors. At year 1 data collection, LPS was still running well, and as the result section shows, a clear improvement in project performance was observed from the baseline to the year 1 data collection. It was later observed that the LPS method was gradually de-implemented. At year 2, only a weekly coordination meeting between superintendents was left. The contractor no longer applied the making ready process, including the seven flows, nor did they make coordinated and valid weekly work plans any longer.

\section{Daily huddles}

During the summer of 2018, the contractor also implemented short daily huddles on the site and weekly whiteboard meetings to identify critical tasks and solve emerging and critical production issues. The weekly whiteboard meetings continued through the construction time, whereas the daily huddles only lasted for around half a year. When the site management removed attention from these daily meetings, superintendents and craftsmen soon began to not conduction daily huddles any longer.

\section{Location-Based Scheduling}

In the spring of 2019, the contractor decided to award a full-time process facilitator to the project. Immediately after that, the process manager started implementing LocationBased Scheduling (LBS) (Seppanen and Kenley 2009). LBS soon became the dominant scheduling and production update tool and continued to be so until the project was completed. It also transformed the weekly meeting, where the process manager was now in charge and navigated through next week's tasks and locations, inspired by the LPS weekly work plan, however, based on a flow-line diagram. Thus meetings were information and coordination meetings, whereas the LPS weekly meetings intended to be Last Planner commitments. In addition, the process manager weekly updated the master plan based on a 12-week lookahead.

\section{Visible site management}

In addition to the well-known lean planning methods above, the contract began in 2019 to focus on the site manager's role on many of their project. The contractor identified that the site manager often tends to be busy in the site office with phone calls, emails, budgets, and spreadsheets instead of assisting the production with fast answers. Therefore, they started implementing visible site management as a concept on several projects, including this one. The purpose was to ensure that the site manager spends more time on-site and less time online! It was quickly realized that, especially during the morning start-up, it had a large effect on the productivity when site managers were accessible out on the site.

\section{Process facilitation}

As written, the contractor decided to add dedicated process facilitation support to the case during the spring of 2019. At that time, the project was behind schedule and above budget. The process facilitation came from the contractor's central lean and process support division and consisted of one full-time facilitator working on the site. His primary 
responsibility was to facilitate LBS implementation and train subcontractors, superintendents, and workers in this method.

\section{RESULTS}

The baseline data, cf. figure 3 and table 1, were collected during normal operation and when no lean methods were implemented and 6 months after construction started.

Table 1: Work Sampling data collected as the baseline.

\begin{tabular}{|c|c|c|c|c|c|c|c|c|}
\hline & & $\begin{array}{l}\text { Direct } \\
\text { Work }\end{array}$ & & $\begin{array}{l}\text { Indirect } \\
\text { Work }\end{array}$ & & & $\begin{array}{l}\text { Waste } \\
\text { Work }\end{array}$ & \\
\hline $\bar{p}$ & (\%) & $26.0 \%$ & & $44.4 \%$ & & & $29.6 \%$ & \\
\hline \multirow[t]{2}{*}{$\mathbf{n}$} & & 7,777 & & 13,257 & & & 8,850 & \\
\hline & & Producing & Talking & Preparing & Transport & Walking & Waiting & Gone \\
\hline $\bar{p}$ & (\%) & $26.0 \%$ & $20.9 \%$ & $15.7 \%$ & $7.7 \%$ & $6.3 \%$ & $6.7 \%$ & $16.6 \%$ \\
\hline
\end{tabular}
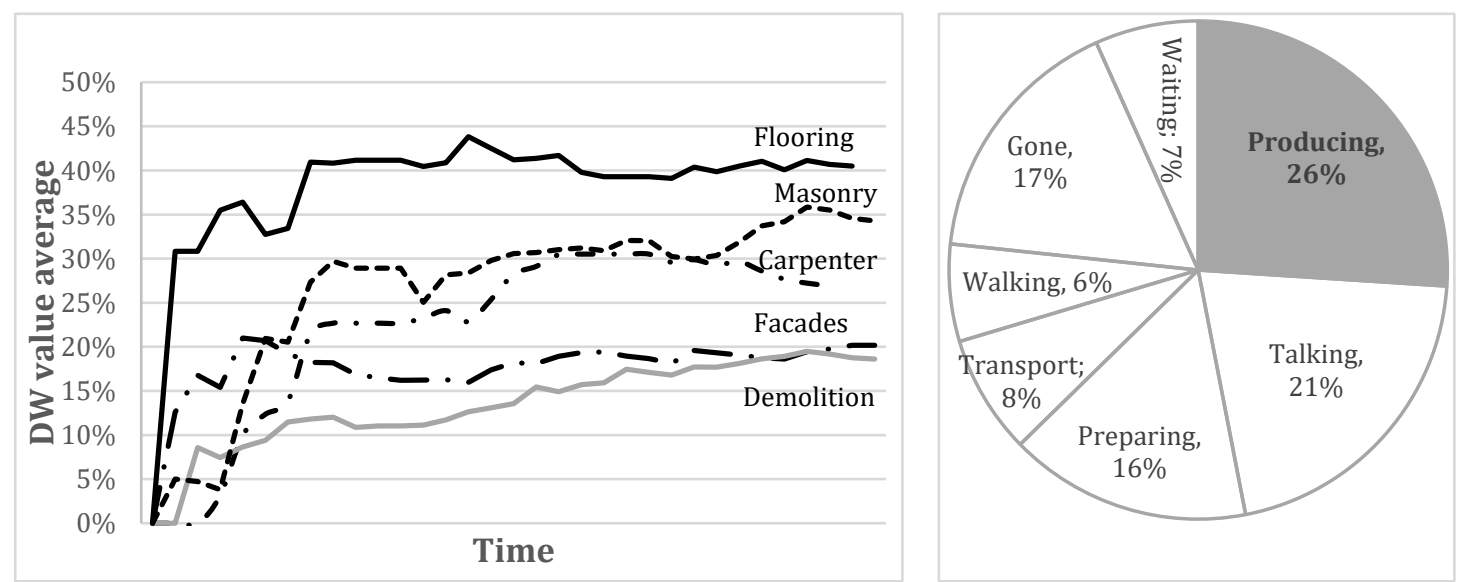

Figure 3. Baseline. Left side: DW Stabilization curves for each trade observed.

Right side: Work Sampling Pie chart ( $\mathrm{n}=24,884)$.

15 months after production started on-site, the year 1 data was collected, cf. figure 4 and table 2. Since the baseline data, the project did implement LPS and Daily huddles meetings, which, however quite fast, was not used more.

Table 2: Work Sampling data collected as of year 1.

\begin{tabular}{|c|c|c|c|c|c|c|c|c|}
\hline & & $\begin{array}{l}\text { Direct } \\
\text { Work }\end{array}$ & & $\begin{array}{l}\text { Indirect } \\
\text { Work }\end{array}$ & & & $\begin{array}{l}\text { Waste } \\
\text { Work }\end{array}$ & \\
\hline$\overline{\boldsymbol{p}}$ & $(\%)$ & $34.0 \%$ & & $40.2 \%$ & & & $25.8 \%$ & \\
\hline \multirow[t]{2}{*}{$\mathrm{n}$} & & 1,534 & & 1,813 & & & 1,160 & \\
\hline & & Producing & Talking & Preparing & Transport & Walking & Waiting & Gone \\
\hline $\bar{p}$ & (\%) & $34.0 \%$ & $11.0 \%$ & $20.2 \%$ & $9.1 \%$ & $10.5 \%$ & $3.6 \%$ & $11.7 \%$ \\
\hline
\end{tabular}



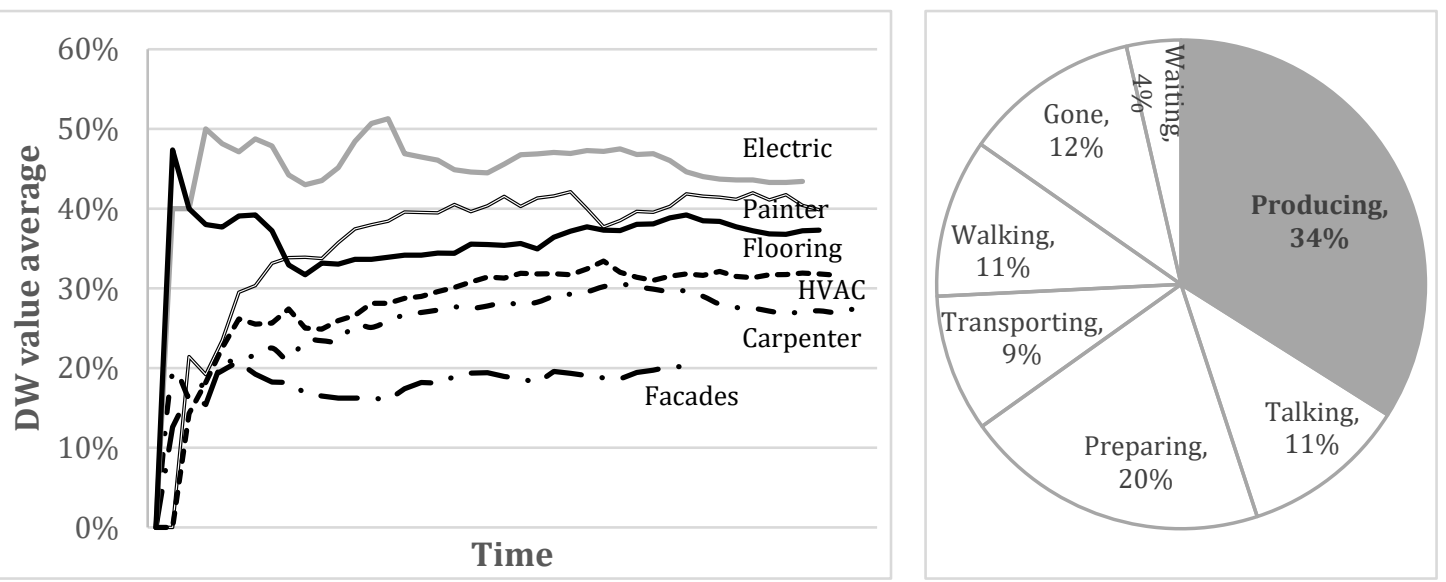

Figure 4. Year 1 data. Left side: DW Stabilization curves for each trade observed. Right side: Work Sampling Pie chart $(n=4,507)$.

24 months after production started on-site, the year 2 data was collected, cf. figure 5 and table 3. Since the year 1 data, the project did implement LBS and the principles of visible site management. Moreover, the site began to have full-time process facilitation support.

Table 3: Work Sampling data collected as of year 2.

\begin{tabular}{|c|c|c|c|c|c|c|c|c|}
\hline & & $\begin{array}{l}\text { Direct } \\
\text { Work }\end{array}$ & & $\begin{array}{c}\text { Indirect } \\
\text { Work }\end{array}$ & & & $\begin{array}{l}\text { Waste } \\
\text { Work }\end{array}$ & \\
\hline$\overline{\boldsymbol{p}}$ & $(\%)$ & $35.1 \%$ & & $38.4 \%$ & & & $26.5 \%$ & \\
\hline \multirow[t]{2}{*}{$\mathbf{n}$} & & 664 & & 725 & & & 502 & \\
\hline & & Producing & Talking & Preparing & Transport & Walking & Waiting & Gone \\
\hline $\bar{p}$ & $(\%)$ & $35.1 \%$ & $10.5 \%$ & $15.5 \%$ & $12.4 \%$ & $11.8 \%$ & $3.7 \%$ & $11.0 \%$ \\
\hline
\end{tabular}
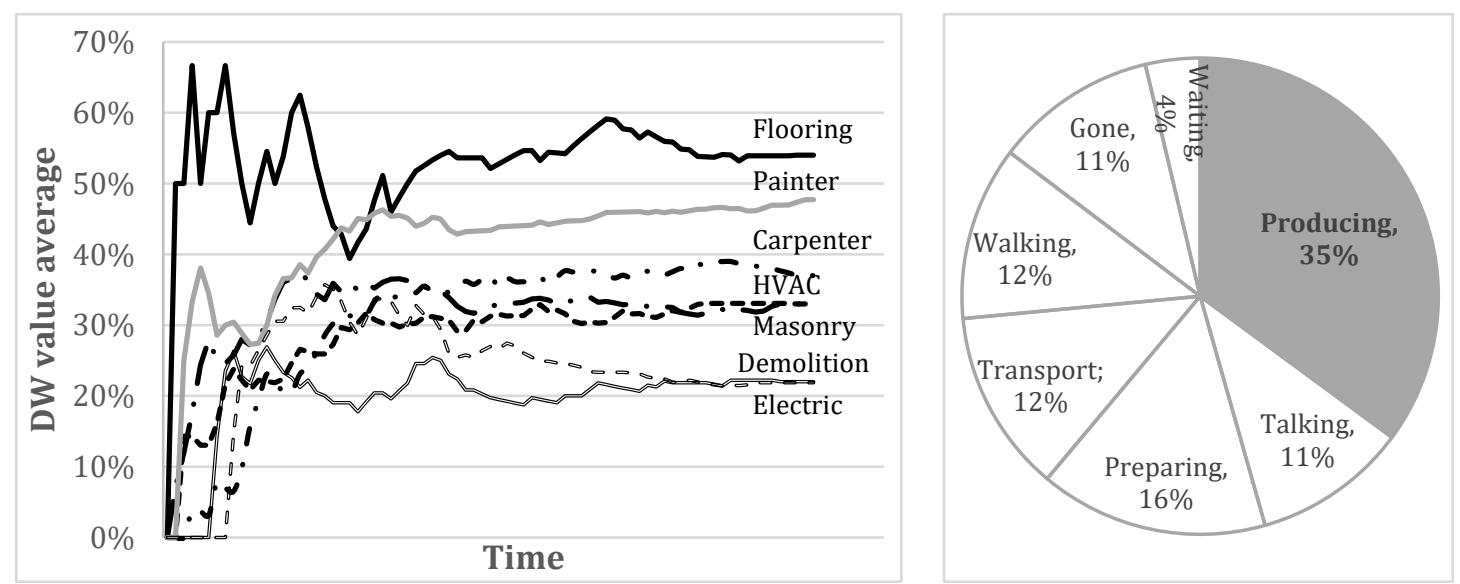

Figure 5. Year 2 data. Left side: DW Stabilization curves for each trade observed. Right side: Work Sampling Pie chart $(n=1,891)$.

35 months after production started on-site, the year 3 data was collected. Since the year 2 data, the project did continue the work to improve the flow, mainly through LBS. The project continued to receive process facilitation support. At the year 3 data collection, no data for each trade was collected. Instead, figure 6 shows the DW distribution during an 
average day. The following Work Sampling data were collected during 5 days, cf. figure 6 and table 4.

Table 4: Work Sampling data collected as of year 3.

\begin{tabular}{|c|c|c|c|c|c|c|c|c|}
\hline & & $\begin{array}{l}\text { Direct } \\
\text { Work }\end{array}$ & & $\begin{array}{l}\text { Indirect } \\
\text { Work }\end{array}$ & & & $\begin{array}{l}\text { Waste } \\
\text { Work }\end{array}$ & \\
\hline $\bar{p}$ & $(\%)$ & $39.6 \%$ & & $30.6 \%$ & & & $29.8 \%$ & \\
\hline \multirow[t]{2}{*}{$\mathrm{n}$} & & 565 & & 436 & & & 424 & \\
\hline & & Producing & Talking & Preparing & Transport & Walking & Waiting & Gone \\
\hline$\overline{\boldsymbol{p}}$ & $(\%)$ & $39.6 \%$ & $8.8 \%$ & $13.4 \%$ & $8.4 \%$ & $14.0 \%$ & $4.2 \%$ & $11.5 \%$ \\
\hline
\end{tabular}
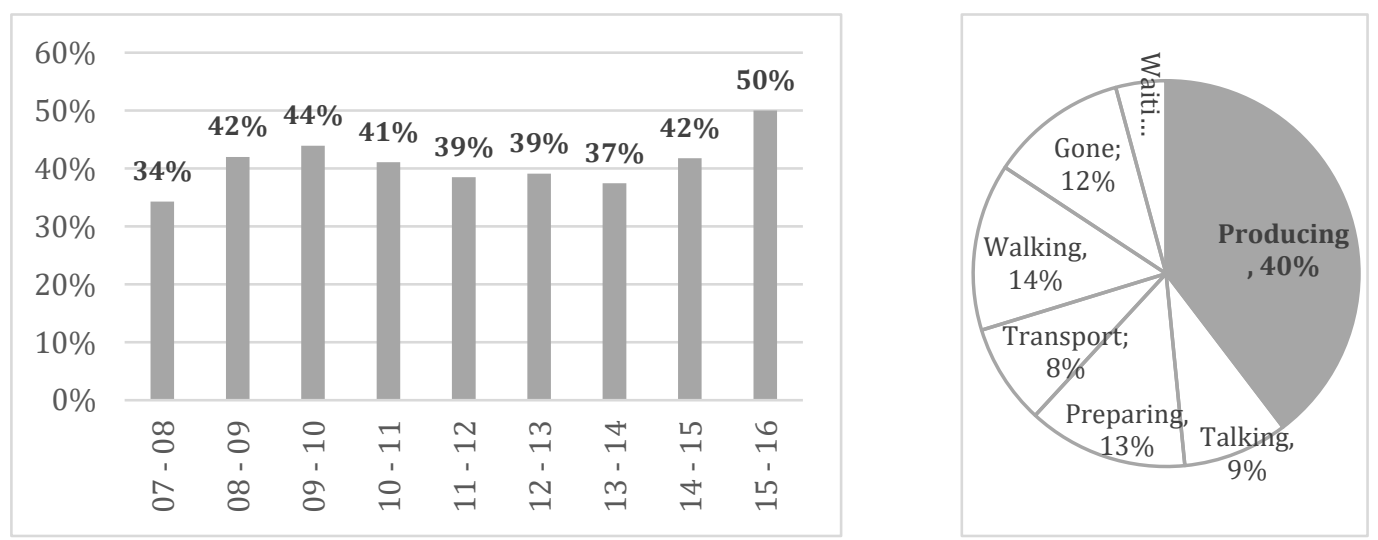

Figure 6. Year 3 data. Left side: average DW values during a workday.

Right side: Work Sampling Pie chart $(n=1,425)$.

\section{DISCUSSION \& CONCLUSION}

A significant increase in productive time was observed in the WS studies from the baseline (no lean implementation) to year three (several lean tools implemented). At year three, the workforce spends more time on value-adding activities, which effectively also mean that the productivity was increased respectively. DW is improved with $54 \%$ from $26 \%$ to $40 \%$, cf. figure 7 . This is a significant improvement.

Improving productivity by $50 \%$ ensures that tasks are conducted at a faster speed, thus the project will be either completed faster or with fewer resources. Both were the situation for the case, as the project was handed over to the client one month before the planned deadline, and the project was able to reduce the on-site labor force by $25 \%$.

Improved on the case is, in particular, talking, which more than halved, showing that planning and coordination improved, leaving fewer issues to be clarified. The credit for this is mainly the implementation of LPS and LBS in combination. Waiting and Gone have also been reduced. Waiting time is reduced by $43 \%$ as an effect of improved flow. In housing renovation, many of the units are similar; thus, the work is repetitive, and it then is important for us as a contractor to get the right takt. The project struggled heavily to get the right takt until the summer of 2019 when location-based scheduling was fully implemented. 


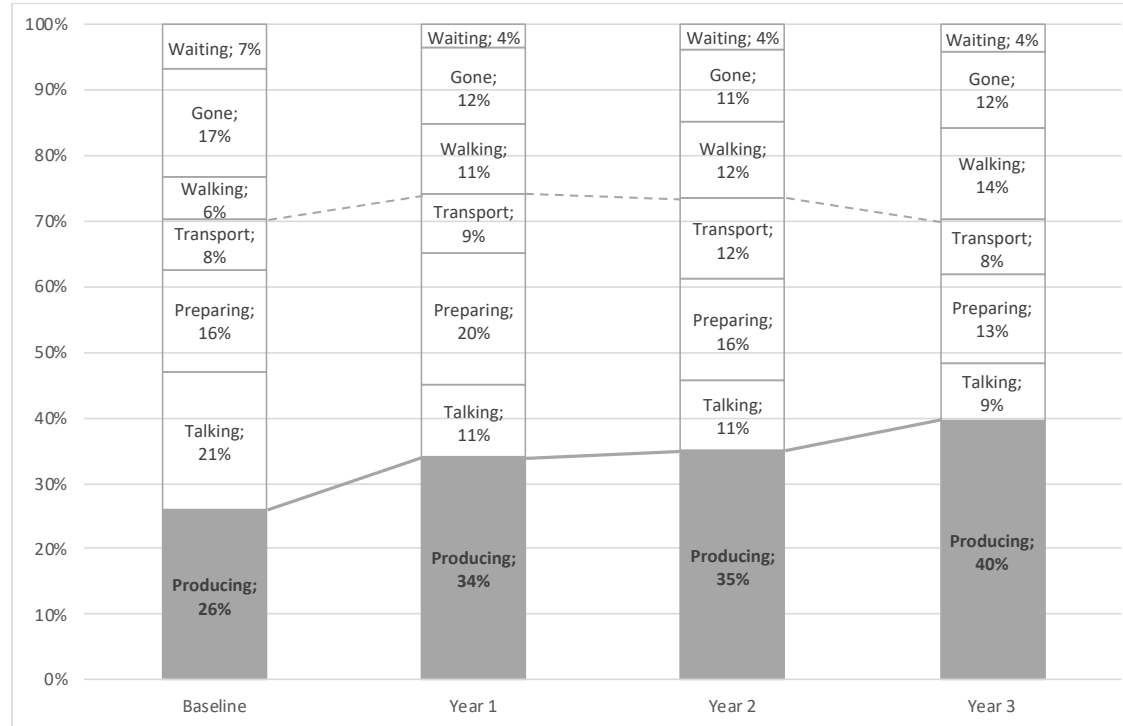

Figure 7. Overview of Work Sampling data over 3 years of the project lifetime.

The logistics were an increasing issue during the project. As work progressed, the construction site layout became less and less effective, as especially the distances from worksite to material storage, equipment containers, and cars, and to site offices and service pavilions increased. Only smaller adjustments were possible due to the layout of existing buildings and the infrastructure of the neighborhood. Overall, movement (walking and transporting) increased $71 \%$ from the baseline to year 2, and then slightly decreased during the last year, however still up 57\% compared to the baseline. This clearly illustrates one of the renovation characteristics: the problem with the existing building's fixed position, making an optimal site layout troublesome. Future research in lean renovation could focus on how to overcome the challenges these renovation characteristics develop.

During the effort to improve flow and productivity, a number of the renovation production system behaviors reported by Neve et al. (2020) were identified in this case also. Firstly, 'case variance': The different trades performed with high variance also over time, cf. figure 3, 4, and 5. Secondly, 'starts and stops': this case showed issues with too much gone time, especially around agreed breaks, which often was too long. Thirdly, 'high performance and high stabilization': As productivity improved on the case, a more stable production flow with less variance was observed. Not only was the performance higher, but also the variance was lower. This is an important lean observation and perhaps the most relevant learning from this research. Nonetheless, more research on understanding renovation production systems and how to optimize these are still needed. Keeping in mind the large amount of renovation anticipated in Europe as well as Worldwide to encounter the green transition of the built environment.

It was clear that the project struggled to implement lean tools and sustain the change, as some elements gradually de-implemented once management focus moved away again. As explained in the Lean elements implemented section, the LPS system was only partially implemented, however still successful in improving performance $(23,5 \%)$ from baseline to year one data collection. Even though LPS was gradually de-implemented after year one, the performance did not decrease similarly as the year two performance shows, cf. figure 7. The secondary data cannot explain this behavior. Lean implementation challenges and partial lean implementation (Wandahl 2014) are widely 
researched. The lean community would benefit from future research on sustaining and instituting change and investigating why lean implementation is sometimes unsuccessful.

In conclusion, this paper demonstrates how flow and productivity can be improved on a single renovation project by implementing different lean tools. Findings are aligned with other research on improving renovation processes (Wandahl and Skovbogaard 2017) and adds to the body of knowledge regarding how lean construction can be applied in renovation projects in particular. Overall, the productivity improved by $54 \%$ from the baseline (6 months into the project) to the completion (3 years).

\section{REFERENCES}

Ballard, G. (2000). "The Last Planner System of Production Control (Ph.D. Thesis)." University of Birmingham.

Bertelsen, S. (2003). "Complexity - A New Way of Understanding Construction." Proc., 11th Annual Conference of the International Group for Lean ConstructionVirginia, USA.

Kemmer, S. (2018). "Development of a Method for Construction Management in Refurbishment Projects." PhD, The University of Huddersfield.

Kemmer, S., Biotto, C., Chaves, F., Koskela, L., and Fazenda, P. T. (2016). "Implementing Last Planner in the Context of Social Housing Retrofit." Proc., 24th Annual Conference of the International Group for Lean ConstructionBoston, Massachusetts, USA.

Kemmer, S., and Koskela, L. (2012). "Developing a Lean Model for Production Management of Refurbishment Projects." Proc., 20th Annual Conference of the International Group for Lean ConstructionSan Diego, California, USA.

Kemmer, S., and Koskela, L. (2014). "Understanding Production Management of Refurbishment Projects of a Housing Association - an Exploratory Case Study." Proc., 22nd Annual Conference of the International Group for Lean ConstructionOslo, Norway, 651-662.

Neve, H. H., and Wandahl, S. (2018). "Towards Identifying Making-Do as Lead Waste in Refurbishment Projects." Proc., 26th Annual Conference of the International Group for Lean ConstructionChennai, India, 1354-1364.

Neve, H. H., Wandahl, S., Lindhard, S., Teizer, J., and Lerche, J. (2020). "Learning to see value-adding and non-value-adding work time in renovation production systems." Production Planning and Control.

Saurin, T. A., Rooke, J., Koskela, L., and Kemmer, S. (2013). "Guidelines for the Management of Complex Socio Technical Systems." Proc., 21th Annual Conference of the International Group for Lean ConstructionFortaleza, Brazil, 13-22.

Seppanen, O., and Kenley, R. (2009). Location-Based Management for Construction.

Tzortzopoulos, P., Kagioglou, M., and Koskela, L. (2020). Lean Construction - Core Concepts and New Frontiers, Routledge, London and New York.

Wandahl, S. (2014). "Lean Construction with or without Lean - Challenges of Implementing Lean Construction." Proc., 22nd Annual Conference of the International Group for Lean ConstructionOslo, Norway, 97-108.

Wandahl, S., and Skovbogaard, J. (2017). "Towards Improving Productivity on Refurbishment Projects." 33rd Annual ARCOM Conference, Cambridge. 